\title{
ADUBAÇÃO E INSETICIDAS NO CONTROLE DE Empoasca kraemeri e Bemisia tabaci, EM CULTIVARES DE FEIJOEIRO SEMEADOS NO INVERNO
}

\author{
Arlindo Leal Boiça Jr. ${ }^{1 *}$; Terezinha Monteiro dos Santos²; Marcus Juabre Muçouçah² \\ ${ }^{1}$ Depto. de Fitossanidade - FCAV/UNESP, Via de Acesso Professor Paulo Donato Castellane, s/n - CEP: 14870-000 - \\ Jaboticabal, SP. \\ ${ }^{2}$ Pós-Graduandos do Depto. de Fitossanidade - FCAV/UNESP. \\ *Autor correspondente <aboicajr@fcav.unesp.br>
}

\begin{abstract}
RESUMO: Vários fatores influenciam a produtividade da cultura do feijoeiro, dentre estes podem ser citados as pragas, merecendo destaque, a cigarrinha verde, Empoasca kraemeri Ross \& Moore (Hemiptera: Cicadellidae) e principalmente a mosca branca, Bemisia tabaci (Gennadius) (Hemiptera: Aleyrodidae), que prejudica o feijoeiro pela transmissão do vírus do mosaico dourado. Este trabalho avalia o efeito de cultivares de feijoeiro, adubação e inseticidas nas populações de E. kraemeri e B. tabaci na época de semeadura "de inverno". Os genótipos utilizados foram IAPAR MD-806, IAPAR MD-808, IAC-Carioca e Bolinha. Avaliaram-se, dos 7 aos 56 dias após emergência das plantas, o número de ninfas e adultos de cigarrinha verde e mosca branca, percentual de ataque de cigarrinha e número de plantas com sintomas de mosaico dourado. Na colheita, foram avaliados 0 número e peso de vagens por planta, o número de grãos por planta e peso de grãos $\left(\mathrm{kg} \mathrm{ha}^{-1}\right)$. Os danos de cigarrinha verde e os sintomas de mosaico dourado foram menos intensos em IAPAR MD-806 e IAPAR MD808 em relação ao Bolinha e IAC-Carioca. A adubação não influenciou o número médio de adultos de cigarrinha verde nos genótipos de feijoeiro. As aplicações de inseticidas e adubo proporcionaram menores números médios de adultos de mosca branca nos genótipos de feijoeiro quando avaliados em conjunto aos 56 dias após emergência das plantas.
\end{abstract}

Palavras-chave: Insecta, mosca branca, cigarrinha, feijão

\section{BEAN CULTIVARS, FERTILIZATION AND INSECTICIDES ON THE CONTROL OF Empoasca kraemeri AND Bemisia tabaci IN THE WINTER SEASON}

\begin{abstract}
The productivity of bean crops is influenced by many factors, among them pests, in particular the leafhopper Empoasca kraemeri Ross \& Moore (Hemiptera: Cicadellidae), and mainly the white fly Bemisia tabaci (Gennadius, 1889) (Hemiptera: Aleyrodidae) that damages the bean crop transmitting the golden mosaic virus. The aim of the present study was to evaluate the effect of bean cultivars, chemical fertilizer and insecticides on E. kraemeri and B. tabaci populations during the winter season. The genotypes IAPAR MD-806, IAPAR MD808 , and IAC-Carioca and Bolinha were analyzed. The number of nymphs and adults of leafhopper and white fly, percentage of leafhopper attack and number of plants with golden mosaic symptoms, from 7 to 56 days after plants emergency were evaluated. The number and weight of the strings per plant, the number of grains per plant and weight of grains ( $\mathrm{kg} \mathrm{ha}^{-1}$ ) were estimated at harvest. The damages caused by the incidence of leafhopper and the golden mosaic symptoms were less intense on the IAPAR MD-806 and IAPAR MD-808 than on Bolinha and IAC Carioca genotypes. The average number of adults of leafhopper was not affected by fertilization. Spraying of insecticides and application of fertilizer caused a lower number of adults of the white fly on the bean genotypes, when evaluated fifty-six days after plant emergency.
\end{abstract}

Key-words: Insecta, white fly, leafhopper, bean

\section{INTRODUÇÃO}

O feijoeiro constitui uma cultura de importância para o país, sendo cultivado em três épocas do ano no Brasil. O plantio de feijão de terceira safra, denominado feijão de inverno, tem contribuído para incrementar a cultura, principalmente em termos de produtividade e minimização de riscos climáticos (Moura et al., 1994).

Vários fatores podem influenciar a produtividade desta cultura, como condições climáticas, cultivares, práticas culturais e principalmente a ocorrência de insetos pragas. Do ponto de vista econômico, Stone \& Sartorato (1994) citam a cigarrinha verde e a mosca branca como as pragas mais importantes.

Os sintomas de ataque da cigarrinha verde são visíveis nas folhas, que se apresentam amareladas, com as bordas enroladas para baixo. As plantas severamente atacadas atrofiam e não se desenvolvem. Os danos são resultantes da sucção de seiva e introdução de substâncias tóxicas durante a alimentação (Sartorato et al., 1987); as plantas têm menor porte, com reduções no comprimento e número de vagens por planta, número e peso de grãos por vagem (Ramalho, 1978). 
Os danos da mosca branca estão associados à transmissão do vírus do mosaico dourado, doença limitante à produção de feijão (Stone \& Sartorato, 1994; Yokoyama, 1996). Em relação aos prejuízos, Almeida et al. (1984) observaram reduções de 43 e $73 \%$, respectivamente, em plantas de feijoeiro infectadas tardia e precocemente pelo mosaico dourado. Paiva \& Goulart (1995) observaram que a população de mosca branca apresentou picos que antecederam à ocorrência de grandes surtos do mosaico dourado em feijoeiro. A queda dos índices de infecção e de população do vetor acompanhou a queda das temperaturas, especialmente quando na ocorrência de temperaturas mínimas abaixo de $15^{\circ} \mathrm{C}$.

Considerando a importância desses insetos para a cultura do feijão, o objetivo do presente trabalho foi estudar o efeito de quatro genótipos de feijoeiro, adubação e inseticidas, nas populações da cigarrinha verde e mosca branca, na época de semeadura "de inverno".

\section{MATERIAL E MÉTODOS}

O experimento foi instalado em solo classificado como Latossolo Vermelho Distrófico Típico (EMBRAPA, 1999), textura argilosa, na área experimental da Faculdade de Ciências Agrárias e Veterinárias, Campus de Jaboticabal, SP. Utilizou-se o delineamento estatístico em blocos casualizados, em esquema fatorial $4 \times 2 \times 2$, representados pelos quatro genótipos de feijoeiro, pela aplicação ou não de inseticidas e aplicação ou não de adubos, totalizando 16 tratamentos. Os genótipos utilizados foram IAPAR MD-806, IAPAR MD-808, IAC-Carioca e Bolinha.

O espaçamento utilizado foi de $0,6 \mathrm{~m}$ entre linhas, numa densidade média de 15 sementes por metro linear. Cada parcela constituiu-se de 6 linhas de $5 \mathrm{~m}$ de comprimento, numa área total de $18,0 \mathrm{~m}^{2}$. A área útil foi de $9,6 \mathrm{~m}^{2}$ pois foram desprezadas duas linhas laterais e $0,5 \mathrm{~m}$ de cada extremidade da parcela, perfazendo um total de $9,6 \mathrm{~m}^{2}$.

De acordo com resultados de análise química do solo, realizou-se uma calagem, com $1500 \mathrm{~kg} \mathrm{ha}^{-1}$ de calcário calcítico, aplicados manualmente em área total, com posterior gradagem e aração para uma adequada incorporação. Nas parcelas com genótipos adubados, aplicaram-se $330 \mathrm{~kg} \mathrm{ha}^{-1}$ de superfosfato simples (pó) acrescido de $30 \mathrm{~kg} \mathrm{ha}^{-1}$ de cloreto de potássio. Uma adubação de cobertura com sulfato de amônio (200 $\left.\mathrm{kg} \mathrm{ha}^{-1}\right)$ foi realizada aos 20 dias após a emergência das plantas.

Utilizaram-se os inseticidas fosfamidom 500 e metamidofós $\mathrm{BR}$ na dose de $0,5 \mathrm{~L} \mathrm{ha}^{-1}$, aplicados semanalmente e alternados, no período de 7 aos 50 dias após a emergência das plantas, através de pulverizador costal manual. Aos 60 dias de emergência das plantas, foi feita uma pulverização geral nas 64 parcelas do experimento, objetivando proteção contra as pragas que atacam as vagens do feijoeiro.

Semanalmente a partir dos 7 aos 56 dias após a emergência das plantas, coletaram-se 15 folíolos por parcela e com auxílio do microscópio estereoscópico, avaliaram-se o número de ninfas de cigarrinha e de mosca branca. A avaliação de adultos foi feita através do método do "chapéu de bruxa", posicionado em dois pontos dentro da área útil de cada parcela.

A percentagem de plantas com sintomas de ataque de cigarrinhas e mosca branca e o número de plantas com sintomas do mosaico dourado foram obtidos quando as plantas atingiram 50 dias de idade.

A colheita das vagens foi efetuada no ponto de maturação fisiológica, avaliando-se: pesos de vagens e grãos, e números de vagens e grãos por planta.

Os dados foram transformados em $\ln (x+1,0)$ e submetidos à análise de variância. As médias foram comparadas pelo teste de Tukey $(P=0,05)$.

\section{RESULTADOS E DISCUSSÃO}

Avaliação da infestação de cigarrinha verde: Aos 14, 35 e 56 dias após emergência das plantas não se verificou diferença significativa em relação ao número médio de ninfas de cigarrinha verde nos genótipos. No entanto, aos 49 dias de idade das plantas, Bolinha apresentou-se com menor infestação em relação aos demais genótipos (TABELA 1). Avaliando os genótipos em conjunto quanto a aplicação de inseticidas, constatou-se que o número médio de ninfas de cigarrinha verde foi semelhante entre os genótipos aos $14 \mathrm{e}$ 56 dias após emergência das plantas. Enquanto aos 35 dias de idade das plantas o número médio de ninfas de cigarrinha verde foi menor quando os genótipos foram pulverizados com inseticidas (TABELA 1).

Aos 21,28 e 42 dias após a emergência das plantas, as interações genótipos $\mathrm{x}$ inseticidas foram significativas em relação à variável número médio de ninfas de cigarrinha verde (TABELA 1). Aos 21 dias na ausência de pulverização com inseticidas os genótipos IAPAR MD-806, IAPAR MD-808 e IAC-Carioca foram menos infestados por ninfas de cigarrinha que Bolinha (TABELA 2). Comparando o número médio de ninfas deste hemíptero dentro de genótipos, pulverizados e não pulverizados com inseticidas, observou-se que Bolinha quando pulverizado apresentou menor número de ninfas, enquanto que nos demais genótipos os inseticidas não influenciaram os números médios de ninfas da cigarrinha. Aos 28 e 42 dias, verificou-se que, sem aplicação de inseticidas, os genótipos IAPAR MD-806 e IAPAR MD-808 apresentaram menores números médios de ninfas de cigarrinhas. Nestes períodos, os genótipos pulverizados com inseticidas apresentaram números médios de cigarrinhas semelhantes. Observando o efeito de inseticidas dentro de genótipos, verificou-se que, aos 28 dias de idade das plantas, os genótipos IAC-Carioca e Bolinha apresentaram menores números médios de cigarrinhas quando pulverizados com inseticidas.

Considerando-se os genótipos em conjunto, em relação a adubação, verificou-se que este tratamento não influenciou o número médio de ninfas de cigarrinha verde durante todas as avaliações, exceto aos 42 dias. No entanto, as interações genótipos $\mathrm{x}$ adubação foram significativas aos 
TABELA 1 - Número médio de ninfas de cigarrinhas em genótipos de feijoeiro quando submetidos ou não a aplicação de inseticidas e adubação. Jaboticabal, SP, 1999.

\begin{tabular}{|c|c|c|c|c|c|c|c|}
\hline \multirow[t]{2}{*}{ Genótipos } & \multicolumn{7}{|c|}{ Dias após emergência das plantas ${ }^{1}$} \\
\hline & 14 & 21 & 28 & 35 & 42 & 49 & 56 \\
\hline IAPAR MD-806 & $0,0000 a$ & $0,0433 \mathrm{~b}$ & $0,0000 \mathrm{~b}$ & $0,1986 a$ & $0,0866 \mathrm{~b}$ & $0,2739 a$ & $0,0000 \mathrm{a}$ \\
\hline IAPAR MD-808 & $0,0000 \mathrm{a}$ & $0,0000 \mathrm{~b}$ & $0,0000 \mathrm{~b}$ & $0,2420 a$ & $0,0866 \mathrm{~b}$ & 0,0687 a & $0,0000 \mathrm{a}$ \\
\hline IAC-Carioca & $0,0000 \mathrm{a}$ & $0,0000 \mathrm{~b}$ & $0,4365 a$ & $0,3539 a$ & $0,3679 a$ & $0,2240 a$ & $0,0433 a$ \\
\hline Bolinha & $0,0866 \mathrm{a}$ & $0,3106 a$ & $0,2673 \mathrm{a}$ & $0,2853 \mathrm{a}$ & $0,3579 a$ & $0,0433 \mathrm{~b}$ & $0,0866 \mathrm{a}$ \\
\hline \multicolumn{8}{|l|}{ Inseticidas } \\
\hline$I_{0}^{12}$ & $0,0217 \mathrm{a}$ & $0,1336 a$ & $0,3521 \mathrm{a}$ & $0,4749 a$ & $0,4259 a$ & $0,3049 a$ & $0,0650 \mathrm{a}$ \\
\hline$\gamma^{2}$ & $0,0217 \mathrm{a}$ & 0,0433 a & $0,0000 \mathrm{~b}$ & $0,0650 \mathrm{~b}$ & $0,0217 \mathrm{~b}$ & $0,0000 \mathrm{~b}$ & $0,0000 \mathrm{a}$ \\
\hline \multicolumn{8}{|l|}{ Adubo } \\
\hline$A_{0}^{/ 3}$ & $0,0217 \mathrm{a}$ & $0,0993 a$ & $0,1896 \mathrm{a}$ & $0,2076 \mathrm{a}$ & $0,1643 \mathrm{~b}$ & 0,903 a & $0,0433 a$ \\
\hline$A^{/ 3}$ & $0,0217 \mathrm{a}$ & $0,0777 \mathrm{a}$ & $0,1623 a$ & $0,3323 a$ & $0,2833 a$ & $0,2146 a$ & $0,0217 \mathrm{a}$ \\
\hline \multicolumn{8}{|l|}{ Interação } \\
\hline$F(G \times I)$ & $0,000 \mathrm{~ns}$ & $4,8785 *$ & $11,1385^{*}$ & $0,2823 \mathrm{~ns}$ & $12,9177^{*}$ & $2,0901 \mathrm{~ns}$ & $1,6337 \mathrm{~ns}$ \\
\hline$F(G \times A)$ & $0,000 \mathrm{~ns}$ & $0,1565 \mathrm{~ns}$ & $0,1014 \mathrm{~ns}$ & $0,6522 \mathrm{~ns}$ & 9,1693 * & $1,8166 \mathrm{~ns}$ & $2,8218^{*}$ \\
\hline
\end{tabular}

TABELA 2 - Valores da análise do desdobramento das interações significativas para o número médio de ninfas de cigarrinhas em genótipos de feijoeiro quando submetidos ou não a aplicação de inseticidas e adubação. Jaboticabal, SP, 1999.

\begin{tabular}{|c|c|c|}
\hline \multirow[t]{2}{*}{ Genótipos } & \multicolumn{2}{|c|}{ Número médio de ninfas de cigarrinhas aos 21 dias $^{11}$} \\
\hline & $\mathrm{I}_{0}^{/ 2}$ & $\mathrm{l}^{2}$ \\
\hline IAPAR MD-806 & $0,0000 \mathrm{Ba}$ & $0,0866 \mathrm{Aa}$ \\
\hline IAPAR MD-808 & $0,0000 \mathrm{Ba}$ & $0,0000 \mathrm{Aa}$ \\
\hline IAC-Carioca & $0,0000 \mathrm{Ba}$ & $0,0000 \mathrm{Aa}$ \\
\hline \multirow[t]{3}{*}{ Bolinha } & $0,5346 \mathrm{Aa}$ & $0,0866 \mathrm{Ab}$ \\
\hline & \multicolumn{2}{|c|}{ Número médio de ninfas de cigarrinhas aos 28 dias $^{1}$} \\
\hline & $\mathrm{I}_{0}$ & 1 \\
\hline IAPAR MD-806 & $0,0000 \mathrm{Ba}$ & $0,0000 \mathrm{Aa}$ \\
\hline IAPAR MD-808 & $0,0000 \mathrm{Ba}$ & $0,0000 \mathrm{Aa}$ \\
\hline IAC-Carioca & $0,8731 \mathrm{Aa}$ & $0,0000 \mathrm{Ab}$ \\
\hline \multirow[t]{3}{*}{ Bolinha } & $0,5346 \mathrm{Aa}$ & $0,0000 \mathrm{Ab}$ \\
\hline & \multicolumn{2}{|c|}{ Número médio de ninfas de cigarrinhas aos 42 dias $^{11}$} \\
\hline & $\mathrm{I}_{0}$ & 1 \\
\hline IAPAR MD-806 & $0,1733 \mathrm{Ba}$ & $0,0000 \mathrm{Aa}$ \\
\hline IAPAR MD-808 & $0,0866 \mathrm{Ba}$ & $0,0000 \mathrm{Aa}$ \\
\hline IAC-Carioca & $0,7358 \mathrm{Aa}$ & $0,0000 \mathrm{Aa}$ \\
\hline \multirow[t]{3}{*}{ Bolinha } & $0,7079 \mathrm{Aa}$ & $0,0000 \mathrm{Aa}$ \\
\hline & \multicolumn{2}{|c|}{ Número médio de ninfas de cigarrinhas aos 42 dias $^{11}$} \\
\hline & $\mathrm{A}_{0}^{13}$ & $\mathrm{~A}^{/ 3}$ \\
\hline IAPAR MD-806 & $0,0866 \mathrm{Aa}$ & $0,0866 \mathrm{Ba}$ \\
\hline IAPAR MD-808 & $0,1733 \mathrm{Aa}$ & $0,0000 \mathrm{Ba}$ \\
\hline IAC-Carioca & $0,0866 \mathrm{Ab}$ & $0,6491 \mathrm{Aa}$ \\
\hline \multirow[t]{3}{*}{ Bolinha } & $0,3106 \mathrm{Aa}$ & $0,3973 \mathrm{Aa}$ \\
\hline & \multicolumn{2}{|c|}{ Número médio de ninfas de cigarrinhas aos 56 dias $^{11}$} \\
\hline & $A^{0}$ & $\mathrm{~A}$ \\
\hline IAPAR MD-806 & $0,0000 \mathrm{Ba}$ & $0,0000 \mathrm{Aa}$ \\
\hline IAPAR MD-808 & $0,0000 \mathrm{Ba}$ & $0,0000 \mathrm{Aa}$ \\
\hline IAC-Carioca & $0,0000 \mathrm{Ba}$ & $0,0866 \mathrm{Aa}$ \\
\hline Bolinha & $0,1733 \mathrm{Aa}$ & $0,0000 \mathrm{Ab}$ \\
\hline
\end{tabular}

${ }^{1}$ Médias seguidas pela mesma letra minúscula na linha e maiúscula na coluna, não diferem pelo teste de Tukey $(P=0,05)$. Dados transformados em In $(\mathrm{x}+1)$.

${ }^{2} \mathrm{I}_{0}=$ sem aplicação de inseticidas e $\mathrm{I}=$ com aplicação de inseticidas.

${ }^{3} \mathrm{~A}_{0}=$ sem adubação e $\mathrm{A}=$ com adubação. 
42 e 56 dias após a emergência das plantas (TABELA 1). Aos 42 dias constatou-se que os genótipos na ausência de adubação apresentaram médias semelhantes de infestação por ninfas de cigarrinha verde (TABELA 2). No entanto, quando adubados os genótipos IAPAR MD-806 e IAPAR-808 apresentaram menores médias de infestação quando comparado aos demais. Observando-se o efeito da adubação dentro de genótipos, verificou-se que IAC-Carioca apresentou maior média de infestação quando adubado. Aos 56 dias os genótipos IAPAR MD-806, IAPAR MD-808 e IAC-Carioca apresentaram menores números médios de ninfas de cigarrinha verde quando não adubado, enquanto não constatou-se diferença estatística em relação ao número médio de insetos entre os genótipos quando estes foram adubados. Com relação ao efeito da adubação dentro de genótipos (TABELA 2) constatou-se menor número médio de ninfas de cigarrinha no genótipo Bolinha quando adubado.

O número médio de adultos de cigarrinha verde (TABELA 3) foi semelhante nos genótipos em todas as avaliações, exceto aos 14 dias, neste período o genótipo IAPAR MD-806 apresentou a menor infestação.

Considerando os quatro genótipos em conjunto, em relação à aplicação de inseticidas, não foi verificado efeito deste tratamento no número médio de adultos da cigarrinha verde (TABELA 3).

Observou-se que durante todos os períodos de avaliações não houve influência da adubação em relação ao número médio de adultos de cigarrinha verde nos genótipos de feijoeiro. No entanto, a interação genótipos $x$ adubação foi significativa aos 21 dias após emergência das plantas de feijoeiro (TABELA 3). Verificou-se que neste período a adubação não influenciou no número médio de adultos da cigarrinha verde nos genótipos avaliados (TABELA 4). Entretanto, quando se considerou o efeito da adubação dentro de genótipos observou-se maior número médio de adultos de cigarrinha no genótipo Bolinha quando na ausência de adubação.

Os genótipos IAPAR MD-806 e IAPAR MD-808 apresentaram os menores percentuais de danos ocasionados pela cigarrinha, evidenciando estes materiais resistência ao ataque da praga (TABELA 5). Quando se aplicou inseticidas, os genótipos apresentaram menores percentuais de danos, no entanto, a adubação não influenciou este parâmetro.

TABELA 4 - Valores da análise do desdobramento das interações significativas para o número médio de adultos de cigarrinhas em genótipos de feijoeiro quando submetidos ou não a aplica ção de adubação. Jaboticabal, SP, 1999.

\begin{tabular}{lcc}
\hline Genótipos & $\begin{array}{c}\text { Número médio de adultos de } \\
\text { cigarrinhas aos 21 dias }\end{array}$ \\
\hline IAPAR MD-806 & $\mathrm{A}_{0}^{/ 2}$ & $\mathrm{~A}^{/ 2}$ \\
IAPAR MD-808 & $0,1733 \mathrm{Aa}$ & $0,2599 \mathrm{Aa}$ \\
IAC-Carioca & $0,2747 \mathrm{Aa}$ & $0,3106 \mathrm{Aa}$ \\
Bolinha & $0,1733 \mathrm{Aa}$ & $0,0000 \mathrm{Aa}$ \\
\hline
\end{tabular}

${ }^{1}$ Médias seguidas pela mesma letra minúscula na linha e maiúscula na coluna, não diferem pelo teste de Tukey $(P=0,05)$. Dados transformados em $\ln (x+1)$.

${ }^{2} A_{0}=$ sem adubação e $A=$ com adubação.

TABELA 3 - Número médio de adultos de cigarrinhas em genótipos de feijoeiro quando submetidos ou não a aplicação de inseticidas. Jaboticabal, SP, 1999.

\begin{tabular}{|c|c|c|c|c|c|c|c|c|}
\hline \multirow{3}{*}{ Genótipos } & \multicolumn{8}{|c|}{ Número médio de adultos de cigarrinhas ${ }^{11}$} \\
\hline & \multicolumn{8}{|c|}{ Dias após a emergência das plantas } \\
\hline & 07 & 14 & 21 & 28 & 35 & 42 & 49 & 56 \\
\hline IAPAR MD-806 & 0,0866 a & $0,0000 \mathrm{~b}$ & 0,2166 a & 0,3106 a & $0,3539 a$ & 0,0866 a & $0,1300 \mathrm{a}$ & $0,5563 \mathrm{a}$ \\
\hline IAPAR MD-808 & 0,1553 a & $0,1986 a b$ & 0,2926 a & 0,1733 a & 0,3289 a & 0,0866 a & $0,2853 \mathrm{a}$ & $0,5112 a$ \\
\hline IAC-Carioca & $0,0000 \mathrm{a}$ & $0,0433 a b$ & 0,0866 a & $0,3286 a$ & 0,2166 a & 0,0866 a & 0,1986 a & $0,5386 a$ \\
\hline Bolinha & $0,1300 \mathrm{a}$ & 0,2835 a & $0,2673 \mathrm{a}$ & 0,0866 a & $0,1300 \mathrm{a}$ & 0,0433 a & 0,2166 a & $0,3413 a$ \\
\hline \multicolumn{9}{|l|}{ Inseticidas (I) } \\
\hline $\mathrm{I}_{0} /{ }^{2}$ & 0,1426 a & $0,1210 \mathrm{a}$ & 0,2763 a & 0,2293 a & $0,2509 \mathrm{a}$ & $0,0600 \mathrm{a}$ & $0,2509 a$ & $0,2726 \mathrm{a}$ \\
\hline $\mathrm{I}^{2}$ & $0,0433 a$ & 0,1426 a & $0,1553 \mathrm{a}$ & $0,2203 \mathrm{a}$ & $0,2636 \mathrm{a}$ & $0,0866 \mathrm{a}$ & $0,1643 a$ & $0,1806 \mathrm{a}$ \\
\hline \multicolumn{9}{|l|}{ Adubo (A) } \\
\hline $\mathrm{A}_{0}^{/ 3}$ & $0,1083 \mathrm{a}$ & $0,1553 \mathrm{a}$ & $0,2890 \mathrm{a}$ & 0,2726 a & 0,3376 a & $0,1083 \mathrm{a}$ & $0,1516 \mathrm{a}$ & $0,1733 \mathrm{a}$ \\
\hline$A^{/ 3}$ & $0,0777 \mathrm{a}$ & $0,1083 \mathrm{a}$ & $0,1426 \mathrm{a}$ & 0,1770 a & 0,1770 a & 0,0433 a & 0,2636 a & $0,2853 \mathrm{a}$ \\
\hline \multicolumn{9}{|l|}{ Interação } \\
\hline$F(G x I)$ & $1,2287 \mathrm{~ns}$ & $2,0407 \mathrm{~ns}$ & $2,0024 \mathrm{~ns}$ & $1,5201 \mathrm{~ns}$ & $0,9750 \mathrm{~ns}$ & $0,1420 \mathrm{~ns}$ & $1,9458 \mathrm{~ns}$ & $2,4806 \mathrm{~ns}$ \\
\hline$F(G \times A)$ & $2,1625 \mathrm{~ns}$ & $1,2300 \mathrm{~ns}$ & $3,0206^{*}$ & $1,4098 \mathrm{~ns}$ & $0,6856 \mathrm{~ns}$ & $0,5505 \mathrm{~ns}$ & $1,6976 \mathrm{~ns}$ & $0,7047 \mathrm{~ns}$ \\
\hline
\end{tabular}

${ }^{1}$ Médias seguidas de mesma letra nas colunas, não diferem pelo teste de Tukey $(P=0,05)$. Dados foram transformados em In $(x+1)$.

${ }^{2} \mathrm{I}_{0}=$ sem aplicação de inseticidas e $\mathrm{I}=$ com aplicação de inseticidas.

${ }^{3} \mathrm{~A}_{0}=$ sem adubação e $\mathrm{A}=$ com adubação. 
Avaliação da infestação de mosca branca: Aos 7, 28, 42 e 49 dias após emergência das plantas não houve influência dos genótipos sobre o número médio de ninfas de mosca branca. No entanto, aos 21 dias de idade das plantas os genótipos IAPAR MD-806 e IAPAR MD-808 foram menos infestados por ninfas de mosca branca em relação ao IAC-Carioca enquanto aos 35 dias IAPAR MD-806 apresentou menor infestação quando comparado ao IAPAR MD-808, mas não diferindo estatisticamente dos demais genótipos (TABELA 6).

TABELA 5 - Avaliação visual (\%) de danos ocasionados pela cigarrinha e número de plantas com sintomas de mosaico dourado, em genótipos de feijoeiro quando submetidos ou não a adubação e aplicação de inseticidas. Jaboticabal, SP, 1999.

\begin{tabular}{|c|c|c|}
\hline Genótipos & $\begin{array}{c}\text { Percentual de } \\
\text { danos ocasionados } \\
\text { pela cigarrinha/1 }\end{array}$ & $\begin{array}{c}\text { Número de } \\
\text { plantas com } \\
\text { mosaico dourado }^{1}\end{array}$ \\
\hline IAPAR MD-806 & $5,7392 \mathrm{~b}$ & $0,0000 \mathrm{~b}$ \\
\hline IAPAR MD-808 & $5,7392 \mathrm{~b}$ & $0,0000 \mathrm{~b}$ \\
\hline IAC-Carioca & 13,0126 a & $0,1986 a b$ \\
\hline Bolinha & $14,9540 \mathrm{a}$ & $0,3679 \mathrm{~b}$ \\
\hline \multicolumn{3}{|l|}{ Inseticidas } \\
\hline $\mathrm{I}_{0}^{12}$ & 11,7520 a & $0,1620 \mathrm{a}$ \\
\hline $\mathrm{P}^{2}$ & $7,9705 \mathrm{~b}$ & $0,1713 \mathrm{a}$ \\
\hline \multicolumn{3}{|l|}{ Adubo } \\
\hline$A_{0}^{/ 3}$ & 9,3799 a & $0,2833 \mathrm{a}$ \\
\hline$A^{/ 3}$ & $10,3426 a$ & $0,0000 \mathrm{~b}$ \\
\hline
\end{tabular}

Avaliando os quatro genótipos em conjunto, observou-se que não houve efeito da aplicação de inseticidas sobre o número médio de ninfas de mosca branca aos 7, 28, 42 e 49 dias após emergência das plantas (TABELA 6). Entretanto aos 21 e 35 dias os genótipos tratados com inseticidas apresentaram menores infestações de ninfas de mosca branca (TABELA 6).

A interação genótipo $x$ inseticidas foi significativa em relação ao parâmetro número médio de ninfas de mosca branca, aos 14 e 56 dias após a emergência das plantas (TABELA 6). Considerando a avaliação aos 14 dias, quando não se aplicou inseticidas, os genótipos IAPAR MD-806, IAPAR MD-808 e Bolinha foram menos infestados pelas ninfas de B. tabaci em comparação ao IAC-Carioca (TABELA 7). No entanto, neste período, quando tratados com inseticidas, os genótipos apresentaram números médios de ninfas de mosca branca semelhantes. Aos 56 dias de emergência das plantas, os genótipos IAPAR MD-806, IAPAR MD-808 e IAC-Carioca tratados ou não com inseticidas apresentaram menores números médios de ninfas de mosca branca em relação ao Bolinha.

Observando o efeito de inseticidas dentro de genótipos verificou-se que aos 14 dias de idade da planta, IAC-Carioca quando pulverizado apresentou menor número médio de ninfas de mosca branca. Enquanto que aos 56 dias, o menor número médio de ninfas de mosca branca foi constatado no genótipo Bolinha quando pulverizado (TABELA 7).

Aos 7, 42 e 49 dias após emergência das plantas não houve influência da adubação em relação ao número médio de ninfas de mosca branca, enquanto aos 14, 21, 28, 35 e 56 dias os genótipos adubados apresentaram menores infestações de ninfas de mosca branca (TABELA 6).

A interação genótipos $x$ adubação em relação ao número médio de ninfas de mosca branca foi significativa

TABELA 6 - Número médio de ninfas de mosca branca em genótipos de feijoeiro quando submetidos ou não a aplicação de inseticidas e adubação. Jaboticabal, SP, 1999.

\begin{tabular}{|c|c|c|c|c|c|c|c|c|}
\hline \multirow[t]{2}{*}{ Genótipos } & \multicolumn{8}{|c|}{ Dias após emergência das plantas ${ }^{1 /}$} \\
\hline & 07 & 14 & 21 & 28 & 35 & 42 & 49 & 56 \\
\hline IAPAR MD-806 & $0,0433 a$ & $0,2420 a b$ & $0,0000 \mathrm{~b}$ & $0,0866 \mathrm{a}$ & $0,1300 \mathrm{~b}$ & $0,0433 a$ & $0,0000 \mathrm{a}$ & $0,0000 \mathrm{~b}$ \\
\hline IAPAR MD-808 & 0,0433 a & $0,0433 \mathrm{~b}$ & $0,0000 \mathrm{~b}$ & $0,1553 \mathrm{a}$ & $0,5346 a$ & $0,1120 \mathrm{a}$ & $0,0433 \mathrm{a}$ & $0,1300 \mathrm{~b}$ \\
\hline IAC-Carioca & 0,0433 a & 0,3539 a & 0,3246 a & 0,1553 a & $0,2240 a b$ & $0,0000 \mathrm{a}$ & $0,0000 \mathrm{a}$ & $0,0000 \mathrm{~b}$ \\
\hline Bolinha & $0,0000 \mathrm{a}$ & $0,1986 a b$ & $0,1120 a b$ & $0,3286 a$ & $0,2853 a b$ & $0,2306 \mathrm{a}$ & 0,0866 a & $0,5551 \mathrm{a}$ \\
\hline \multicolumn{9}{|l|}{ Inseticida } \\
\hline 10/2 & $0,0433 \mathrm{a}$ & 0,2546 a & $0,1750 \mathrm{a}$ & $0,2420 \mathrm{a}$ & 0,4316 a & 0,1496 a & $0,0650 \mathrm{a}$ & $0,3425 a$ \\
\hline $\mathrm{I}_{12}$ & $0,0217 \mathrm{a}$ & $0,1643 \mathrm{a}$ & $0,0433 \mathrm{~b}$ & $0,1210 \mathrm{a}$ & $0,1553 \mathrm{~b}$ & $0,0433 \mathrm{a}$ & $0,0000 \mathrm{a}$ & $0,0000 \mathrm{a}$ \\
\hline \multicolumn{9}{|l|}{ Adubo } \\
\hline$A_{0}^{/ 3}$ & $0,0217 \mathrm{a}$ & $0,3539 \mathrm{a}$ & $0,1750 \mathrm{a}$ & $0,2853 \mathrm{a}$ & $0,4099 \mathrm{a}$ & $0,1496 \mathrm{a}$ & $0,0217 \mathrm{a}$ & $0,2306 \mathrm{a}$ \\
\hline$A^{/ 3}$ & $0,0433 \mathrm{a}$ & $0,0650 \mathrm{~b}$ & $0,0433 \mathrm{~b}$ & $0,0777 \mathrm{~b}$ & $0,1770 \mathrm{~b}$ & $0,0433 \mathrm{a}$ & $0,0433 a$ & $0,1120 \mathrm{~b}$ \\
\hline \multicolumn{9}{|l|}{ Interação } \\
\hline$F(G x I)$ & $1,4103 \mathrm{~ns}$ & $5,0278^{*}$ & $1,7693 \mathrm{~ns}$ & $2,7067 \mathrm{~ns}$ & $1,9446 \mathrm{~ns}$ & $2,0716 \mathrm{~ns}$ & $1,1702 \mathrm{~ns}$ & $33,2843^{*}$ \\
\hline$F(G \times A)$ & $1,4103 \mathrm{~ns}$ & $1,0402 \mathrm{~ns}$ & $1,7693 \mathrm{~ns}$ & $0,9158 \mathrm{~ns}$ & $2,6241 \mathrm{~ns}$ & $2,0716 \mathrm{~ns}$ & $0,3191 \mathrm{~ns}$ & $4,0675^{*}$ \\
\hline
\end{tabular}

${ }^{1}$ Médias seguidas de mesma letra nas colunas, não diferem pelo teste de Tukey $(P=0,05)$. Dados foram transformados em In $(x+1)$.

${ }^{2} \mathrm{I}_{0}=$ sem aplicação de inseticidas e $\mathrm{I}=$ com aplicação de inseticidas.

${ }^{3} A_{0}=$ sem adubação e $A=$ com adubação. 
TABELA 7 - Valores da análise do desdobramento das interações significativas para o número médio de ninfas de mosca branca em genótipos de feijoeiro quando submetidos ou não a aplicação de adubação e inseticidas. Jaboticabal, SP, 1999.

\begin{tabular}{|c|c|c|}
\hline \multirow[t]{2}{*}{ Genótipos } & \multicolumn{2}{|c|}{$\begin{array}{l}\text { Número médio de ninfas de mosca } \\
\text { branca aos } 14 \text { dias }^{11}\end{array}$} \\
\hline & $\mathrm{I}_{0}^{/ 2}$ & $\gamma^{2}$ \\
\hline IAPAR MD-806 & $0,1733 \mathrm{Ba}$ & $0,3160 \mathrm{Aa}$ \\
\hline IAPAR MD-808 & $0,0000 \mathrm{Ba}$ & $0,0866 \mathrm{Aa}$ \\
\hline IAC-Carioca & $0,6212 \mathrm{Aa}$ & $0,0866 \mathrm{Ab}$ \\
\hline \multirow[t]{3}{*}{ Bolinha } & $0,2240 \mathrm{Ba}$ & $0,1733 \mathrm{Aa}$ \\
\hline & \multicolumn{2}{|c|}{$\begin{array}{l}\text { Número médio de ninfas de mosca } \\
\text { branca aos } 56 \text { dias }^{11}\end{array}$} \\
\hline & $\mathrm{I}_{0}$ & I \\
\hline IAPAR MD-806 & $0,0000 \mathrm{Ba}$ & $0,0000 \mathrm{Ba}$ \\
\hline IAPAR MD-808 & $0,1733 \mathrm{Ba}$ & $0,0866 \mathrm{Ba}$ \\
\hline IAC-Carioca & $0,0000 \mathrm{Ba}$ & $0,0000 \mathrm{Ba}$ \\
\hline \multirow[t]{3}{*}{ Bolinha } & $0,7489 \mathrm{Aa}$ & $0,3613 \mathrm{Ab}$ \\
\hline & \multicolumn{2}{|c|}{$\begin{array}{l}\text { Número médio de ninfas de mosca } \\
\text { branca aos } 56 \text { dias }^{11}\end{array}$} \\
\hline & $\mathrm{A}_{0}^{/ 3}$ & $\mathrm{~A}^{/ 3}$ \\
\hline IAPAR MD-806 & $0,0000 \mathrm{Ca}$ & $0,0000 \mathrm{Aa}$ \\
\hline IAPAR MD-808 & 0,2599 Ba & $0,0000 \mathrm{Ab}$ \\
\hline IAC-Carioca & $0,0000 \mathrm{Ca}$ & $0,0000 \mathrm{Aa}$ \\
\hline Bolinha & $1,1102 \mathrm{Aa}$ & $0,0000 \mathrm{Ab}$ \\
\hline
\end{tabular}

aos 56 dias de emergência das plantas (TABELA 6). Nesta avaliação, observou-se que na ausência de adubação, IAPAR MD-806, IAPAR MD-808 e IAC-Carioca foram menos infestados por ninfas de mosca branca em relação ao Bolinha (TABELA 7).

Relacionando-se o efeito da adubação dentro de genótipos observou-se que IAPAR MD-808 e Bolinha aos 56 dias após emergência, quando adubados apresentaram menores números médios de ninfas de mosca branca, enquanto que para os demais genótipos esta variável não foi influenciada pela adubação (TABELA 7).

Aos 49 e 56 dias após emergência das plantas de feijão, verificou-se que os genótipos IAPAR MD-806, IAPAR MD-808 e Bolinha apresentaram menores números médios de adultos de $B$. tabaci em comparação ao IACCarioca (TABELA 8), enquanto, nos demais períodos de avaliações esses números foram semelhantes entre estes genótipos. As aplicações de inseticidas e adubo proporcionaram menores números médios de adultos de mosca branca considerando-se os genótipos em conjunto aos 56 dias após emergência das plantas (TABELA 8).

Com relação ao número de plantas com sintomas de mosaico dourado, verificou-se que o genótipo Bolinha apresentou a maior média para esse parâmetro (TABELA 5). A aplicação de inseticidas não influenciou a ocorrência dos sintomas de viroses, enquanto que os genótipos adubados apresentaram menores incidências de sintomas de viroses (TABELA 5).

Análise dos dados de produtividade: o genótipo IAPAR MD-806 apresentou-se com pesos de vagens e de grãos, bem como número de vagens/planta e número de grãos/ planta maiores em relação aos demais genótipos. As aplicações de inseticidas e adubo não influenciaram esses parâmetros de produtividade (TABELA 9).

TABELA 8 - Número médio de adultos de mosca branca em genótipos de feijoeiro quando submetidos ou não a aplicação de inseticidas e adubação. Jaboticabal, SP, 1999.

\begin{tabular}{|c|c|c|c|c|c|c|}
\hline \multirow[t]{2}{*}{ Genótipos } & \multicolumn{6}{|c|}{ Dias após emergência das plantas ${ }^{11}$} \\
\hline & 14 & 28 & 35 & 42 & 49 & 56 \\
\hline IAPAR MD-806 & $0,0000 \mathrm{a}$ & 0,0433 a & $0,0000 \mathrm{a}$ & $0,0000 \mathrm{a}$ & $0,2420 \mathrm{~b}$ & $0,2420 b$ \\
\hline IAPAR MD-808 & $0,0433 \mathrm{a}$ & $0,0000 \mathrm{a}$ & $0,0000 \mathrm{a}$ & $0,0000 \mathrm{a}$ & $0,3793 a b$ & $0,4046 \mathrm{~b}$ \\
\hline IAC-Carioca & 0,0433 a & $0,0433 \mathrm{a}$ & $0,0000 \mathrm{a}$ & $0,0000 \mathrm{a}$ & $0,7398 \mathrm{a}$ & 0,8657 a \\
\hline Bolinha & $0,0000 \mathrm{a}$ & $0,0000 \mathrm{a}$ & 0,0433 a & 0,0433 a & $0,2673 \mathrm{~b}$ & $0,3135 b$ \\
\hline \multicolumn{7}{|l|}{ Inseticidas } \\
\hline $\mathrm{I}_{0}^{12}$ & $0,0000 \mathrm{a}$ & $0,0000 \mathrm{a}$ & $0,0000 \mathrm{a}$ & $0,0000 \mathrm{a}$ & 0,4876 a & $0,5844 a$ \\
\hline 12 & 0,0433 a & 0,0433 a & $0,0217 \mathrm{a}$ & $0,0217 \mathrm{a}$ & 0,3266 a & $0,3266 \mathrm{~b}$ \\
\hline \multicolumn{7}{|l|}{ Adubo } \\
\hline $\mathrm{A}_{0}^{1 / 3}$ & $0,0217 \mathrm{a}$ & $0,0217 \mathrm{a}$ & 0,0217 a & $0,0000 \mathrm{a}$ & 0,4946 a & $0,5722 \mathrm{a}$ \\
\hline $\mathrm{A}^{/ 3}$ & 0,0217 a & 0,0217 a & $0,0007 \mathrm{a}$ & $0,0217 \mathrm{a}$ & $0,3196 \mathrm{a}$ & $0,3392 \mathrm{~b}$ \\
\hline \multicolumn{7}{|l|}{ Interação } \\
\hline$F(G x l)$ & $0,7146 \mathrm{~ns}$ & $1,0000 \mathrm{~ns}$ & $1,0000 \mathrm{~ns}$ & $1,0000 \mathrm{~ns}$ & $0,1854 \mathrm{~ns}$ & $0,2731 \mathrm{~ns}$ \\
\hline$F(G \times A)$ & $1,4286 \mathrm{~ns}$ & $1,0000 \mathrm{~ns}$ & $1,0000 \mathrm{~ns}$ & $1,0000 \mathrm{~ns}$ & $0,6309 \mathrm{~ns}$ & $0,7793 \mathrm{~ns}$ \\
\hline
\end{tabular}

${ }^{1}$ Médias seguidas de mesma letra nas colunas, não diferem pelo teste de Tukey $(P=0,05)$. Dados foram transformados em $\ln (x+1)$. ${ }^{2} \mathrm{I}_{0}=$ sem aplicação de inseticidas e I = com aplicação de inseticidas.

${ }^{3} \mathrm{~A}_{0}=$ sem adubação e $\mathrm{A}=$ com adubação. 
TABELA 9 - Pesos e números de vagens e de grãos em genótipos de feijoeiro quando submetidos ou não a adubação e aplicação de inseticidas. Jaboticabal, SP, 1999.

\begin{tabular}{|c|c|c|c|c|}
\hline Genótipos & Peso de vagens ${ }^{11}$ & Peso de grãos ${ }^{11}$ & Número de vagens/planta ${ }^{1}$ & Número de grãos/planta ${ }^{1 /}$ \\
\hline & g por planta & $\mathrm{kg} \mathrm{ha}^{-1}$ & & \\
\hline IAPAR MD-806 & $1,6355 \mathrm{a}$ & 6,1176 a & $1,5177 \mathrm{a}$ & $2,6641 \mathrm{a}$ \\
\hline IAPAR MD-808 & $1,2805 \mathrm{~b}$ & $5,6766 \mathrm{c}$ & $1,2878 a b$ & $2,3115 a b$ \\
\hline IAC-Ccarioca & $1,2594 \mathrm{~b}$ & $5,7181 \mathrm{bc}$ & $1,2597 \mathrm{~b}$ & $2,2146 b$ \\
\hline Bolinha & $1,3974 a b$ & $5,7334 \mathrm{bc}$ & $1,3566 a b$ & $2,1109 \mathrm{~b}$ \\
\hline \multicolumn{5}{|l|}{ Inseticida (I) } \\
\hline $\mathrm{I}_{0}^{1 / 2}$ & $1,3737 \mathrm{a}$ & 5,8198 a & $1,3451 \mathrm{a}$ & $2,3269 a$ \\
\hline$\gamma^{2}$ & $1,4627 \mathrm{a}$ & $5,9531 \mathrm{a}$ & $1,3658 \mathrm{a}$ & $2,3267 \mathrm{a}$ \\
\hline \multicolumn{5}{|l|}{ Adubo (A) } \\
\hline $\mathrm{A}_{0}^{/ 3}$ & $1,3829 a$ & $5,8540 \mathrm{a}$ & $1,3284 \mathrm{a}$ & $2,2704 \mathrm{a}$ \\
\hline$A^{/ 3}$ & 1,4553 a & $5,9189 a$ & $1,3825 \mathrm{a}$ & $2,3801 \mathrm{a}$ \\
\hline \multicolumn{5}{|l|}{ Interação } \\
\hline$F(G \times I)$ & $1,7294 \mathrm{~ns}$ & $0,2719 \mathrm{~ns}$ & $0,5009 \mathrm{~ns}$ & $1,2832 \mathrm{~ns}$ \\
\hline$F(G \times A)$ & $1,4064 \mathrm{~ns}$ & $0,4464 \mathrm{~ns}$ & $0,6102 \mathrm{~ns}$ & $0,6514 \mathrm{~ns}$ \\
\hline
\end{tabular}

${ }^{1}$ Médias seguidas de mesma letra nas colunas não diferem pelo teste de Tukey $(P=0,05)$. Dados foram transformados em In $(x+1)$.

${ }^{2} \mathrm{I}_{0}=$ sem aplicação de inseticidas e I = com aplicação de inseticidas.

${ }^{3} \mathrm{~A}_{0}=$ sem adubação e $\mathrm{A}=$ com adubação.

\section{REFERÊNCIAS BIBLIOGRÁFICAS}

ALMEIDA, L. D. de; PEREIRA, J. C. V. N. A.; RONZELLI JÚNIOR, P.; COSTA, A. S. Avaliação de perdas causadas pelo mosaico dourado do feijoeiro (Phaseolus vulgaris L.) em condições de campo. Fitopatologia Brasileira, v.9, p.213-219, 1984.

EMBRAPA. Centro Nacional de Pesquisa de Solos. Sistema brasileiro de classificação de solos. Brasília, 1999. 412 p.

MOURA, P. A. M. de; PAIVA, B. M. de; RESENDE, L. M. A. Aspectos econômicos da cultura do feijão. Informe Agropecuário, v.17, p.69-72, 1994.

PAIVA, F. A. L.; GOULART, A. C. P. Flutuação populacional da mosca branca e incidência de mosaico do feijoeiro em Dourados, MS. Fitopatologia Brasileira, v.20, p.199-202, 1995.
RAMALHO, F. S. Efeitos da época de infestação da cigarrinha verde Empoasca kraemeri Ross \& Moore, 1957 (Homoptera: Typhlocibidae). Anais da Sociedade Entomológica do Brasil, v.7, p.30-32, 1978.

SARTORATO, A.; RAVA, C. A.; YOKOYAMA, M. Principais doenças e pragas do feijoeiro comum no Brasil. Santo Antônio de Goiás: EMBRAPA, CNPAF, 1987. p.38-40.

STONE, L. F.; SARTORATO, A. O cultivo do feijão: recomendações técnicas. Brasília: EMBRAPA, 1994. 83 p.

YOKOYAMA, M. Principais pragas e seu controle. In: ARAÚJO, R. S.; RAVA, C. A.; STONE, L. F.; ZIMMERMANN, M. J. O. Cultura do feijoeiro comum no Brasil. Piracicaba: Potafós, 1996. p.771-786.

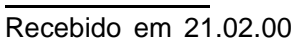

